\title{
Estudos de elites políticas e sociais: as contribuições da Sociologia e da História
}

\author{
Lorena Monteiro \\ Doutoranda em Ciência Política (Universidade Federal do Rio Grande do Sul) \\ Porto Alegre, Brasil \\ lorena.madruga@bol.com.br
}

\begin{abstract}
Resumo Este trabalho tem como objetivo investigar a relação entre a análise sociológica e as elites situadas historicamente. Esta escolha justificou-se por dois motivos: primeiro, porque, nas últimas décadas, a imbricação entre a pesquisa histórica e os estudos sociológicos sobre as elites é um tema dominante nas Ciências Sociais, especialmente na França, e, segundo, porque a análise teórico-metodológica dessa relação carece de delimitações, especialmente para analisar as elites intelectuais em contextos periféricos, como o caso do Brasil. Desse modo, demonstramos, num primeiro momento, como esses esquemas teóricos foram utilizados em algumas pesquisas históricas. Após, abordamos o tipo de tratamento sociológico empregado nas trajetórias históricas, tanto individuais quanto de grupos de elites, para, por fim, expor um dos recursos metodológicos disponíveis entre a pesquisa histórica e a análise sociológica: a prosopografia.
\end{abstract}

Palavras-chaves: elites; Sociologia; História; prosopografia.

$\mathrm{O}$ TERMO ELITE SE REFERE, de forma geral, e um tanto imprecisa, àqueles indivíduos pertencentes aos grupos melhores situados na estrutura social como um todo. Esse termo surgiu com as obras de Mosca e Pareto sobre as características elitistas da minoria que detinha o poder, ${ }^{1}$ foi radicalizado com a noção de classe dominante pelo marxismo, ${ }^{2}$ e adquiriu corpo com as proposições de Mills (1959) sobre os grupos no poder. Nos anos 1960, esse termo teve seu caráter monolítico contestado pelas pesquisas locais daqueles que defendiam a natureza pluralista das elites, como Dahl (1961) e Putnam (1976). Posteriormente a esse período poucas contribuições surgiram na Ciência Política em relação a este debate (Scott, 1995).

Isto está relacionado à ascensão das teorias neoinstitucionalistas, a partir dos anos 1970, que direcionaram o foco da análise ao papel das instituições como preditivas do comportamento e da ação daqueles identificados como parte dos grupos dirigentes e não tanto ao tipo de elite no poder como fator determinante dos processos políticos. Juntase a essa vertente teórica o neoinstitucionalismo histórico, que enfatizou o Estado como promotor da dinâmica política, especialmente com os estudos de Theda Skocpol (1989).

Com essa orientação encontram-se na Ciência Política, atualmente, os trabalhos específicos sobre elites políticas que se detêm nas diferentes formas de recrutamento e de carreiras políticas. A partir do princípio liberal da competição democrática, esses estudos demonstram os

1 Para uma análise mais completa sobre o surgimento da chamada Teoria das Elites, ver: Grynszpan (1999).

2 Ver especialmente Martuscelli (2007). 
padrões de carreiras e a profissionalização do político como um indicador da institucionalização da política (Santos, 2000; Serna, 2007; Santos e Serna, 2007).

Situação inversa encontra-se na interpretação sociológica das elites com base em pesquisas históricas. Por isso, este trabalho centra-se na relação entre análise sociológica e elites situadas historicamente. Esta escolha justifica-se por dois motivos: primeiro, porque, nas últimas décadas, a imbricação entre a pesquisa histórica e os estudos sociológicos sobre as elites é um tema dominante nas Ciências Sociais, especialmente na França, e, segundo, porque a análise teórico-metodológica dessa relação carece de delimitações, especialmente para analisar elites intelectuais em contextos periféricos, como o caso do Brasil.

Argumenta-se, desse modo, que uma elite social, intelectual e/ou política não é algo dado, é, antes de mais nada, um fenômeno social e histórico a ser explorado, e, enquanto tal, deve ser apreendido, tanto pela suas bases e atributos sociais quanto pelas suas práticas sociais, tomadas de posição, em um dado contexto histórico. Portanto, esta é a perspectiva adotada neste trabalho com o objetivo de demonstrar as possibilidades e limitações da pesquisa histórica aliada à análise sociológica daqueles grupos identificados como elites.

\section{Situando as elites na perspectiva da História e da Sociologia}

Nas últimas décadas, os estudos sociológicos sobre elites políticas e culturais deram constantes contribuições à disciplina histórica, por um lado por influência dos trabalhos de Pierre Bourdieu e do grupo da revista Actes de Recherche en Sciences Sociales e, por outro, pelas explicações diacrônicas dos processos de mobilizações sociais contidas nas obras de Charles Tilly (1978, 1993) e Sidney Tarrow (1994).

Ambas as perspectivas têm em comum a percepção do objeto sociológico como produto histórico, embora com objetivos distintos. Enquanto os trabalhos de Bourdieu e de seu grupo demonstraram a resistência histórica de certas estruturas sociais como longos processos de dominação, Charles Tilly e Sidney Tarrow preocuparam-se com as possibilidades de mobilização social em períodos de crises sociais.

Não se pretende aqui aprofundar as contribuições dessas teorias nos estudos de elites, apenas delinear brevemente, através de alguns estudos representativos e de metodologias, a imbricação da História e da Sociologia na análise de elites sociais. Desse modo, demonstramos, num primeiro momento, como esses esquemas teóricos foram aplicados em algumas pesquisas históricas. Em seguida, abordamos o tipo de tratamento sociológico empregado nas trajetórias his- tóricas, tanto individuais quanto de grupos de elites, para, por fim, expor um dos recursos metodológicos disponíveis entre a pesquisa histórica e a análise sociológica: a prosopografia.

\section{Cultura e experiência: construções intelectuais e práticas sociais}

Desde os trabalhos históricos de Jean-François Sirinelli (1989; 1990; Rioux e Sirinelli, 2005) e das questões levantadas pela Sociologia da Cultura, "a história política passou por um verdadeiro renascimento, no qual há um interesse renovado não apenas pelas elites políticas, mas também pelas elites intelectuais" (Altamirano, 2007, p. 2). Mesmo assim, esse maior interesse está vinculado a uma espécie de história intelectual que pouco se afastou da História das Ideias, ou melhor, da imaginação social e política das elites intelectuais. Dessa forma, a partir de temas históricos, quem renovou a área sobre elites culturais e intelectuais foram as teorias sociológicas, que relacionaram os contextos históricos nos quais os atores estiveram inseridos e produziram suas ideias com o sentido de suas construções intelectuais, práticas sociais e políticas.

A obra $A$ construção da ordem, de José Murilo de Carvalho, foi pioneira no estudo da formação das elites num contexto historicamente situado - o período imperial brasileiro -, afastando-se da História das Ideias ou do Pensamento e dedicando-se à problemática da formação escolar e dos padrões de carreira política. Carvalho (1980) escolheu essa elite pelo seu caráter homogêneo em termos de treinamento e formação escolar. Por isso, a elite brasileira no período representava uma ilha de letrados num mar de analfabetos. Esse treinamento homogêneo, especialmente a formação jurídica, era dado pela Universidade de Coimbra, e posteriormente em algumas capitais provinciais. Esses centros de saber muniram a elite de uma ideologia homogênea. Desse modo, a formação da geração de Coimbra predominou durante a fase de consolidação política do sistema imperial e, a partir daí, foi substituída pela geração brasileira. Essa estabilidade do sistema político brasileiro também se refere à construção de várias carreiras políticas e à acumulação de vasta experiência de governo.

Carvalho (1980) ressaltou que ocorria uma circulação de administradores por vários postos e regiões, garantindo a estabilidade e evitando uma intimidade dos políticos com os problemas locais, o que poderia gerar rebeliões. Ou seja, essa circulação tinha papel estratégico e teve um efeito unificador poderoso. Portanto, Carvalho (1980), ao centrar sua análise nas características sociais e políticas comuns dessa elite, afastou-se de uma análise centrada nas ideias difundi- 
das por esses grupos de forma descontextualizada no período em questão.

Noutro sentido, situamos a obra de Fritz Ringer (2000), O declínio dos mandarins alemães, como um exemplo de distanciamento da História Intelectual, ao aproximar as experiências comuns desses intelectuais, no contexto do processo de modernização da Alemanha, com suas opiniões sobre as transformações sociais e políticas em curso. Essa elite social e cultural tinha esse status de mandarins muito mais pelas suas qualificações educacionais do que por sua riqueza ou pelos direitos adquiridos. Sua ascensão esteve relacionada a um estágio intermediário do desenvolvimento capitalista, quando o capital econômico não era amplamente valorizado como qualificação de status social. Embora fosse uma comunidade intelectual extremamente integrada e homogênea, especialmente pelo mesmo tipo de escolarização e status social, quando estiveram ameaçados pelas transformações na estrutura social, decorrentes do desenvolvimento econômico, demonstraram pontos de vista diversificados, dividindo-se entre aqueles que o autor classificou como os ortodoxos e os modernistas.

Portanto, Ringer (2000) contribuiu para a análise das elites intelectuais ao ter articulado esse contexto histórico de mudanças sociais profundas com as experiências compartilhadas desses intelectuais e a posição deles, através das suas opiniões, sobre a realidade na qual estavam inseridos. Ângela Alonso (2002) seguiu uma direção similar ao analisar um tema histórico - a geração de 1870 no Brasil - e dar um tratamento sociológico a este objeto, do mesmo modo que Ringer fez com a elite acadêmica alemã - os mandarins - no final do século XIX e início do XX.

A geração de 1870 no Brasil foi composta por aqueles que se posicionaram criticamente em relação às instituições imperiais. Até a análise de Ângela Alonso, os estudos existentes referiam-se às escolas de pensamento europeias às quais o grupo filiava-se, como o cientificismo, o evolucionismo e o positivismo. Como demonstrou Ângela Alonso (2002), tratar movimentos intelectuais apenas a partir das ideias propagadas por um grupo de autores pressupõe a existência de um campo intelectual autônomo às outras esferas do espaço social no período referido, especialmente à política, o que não ocorria.

De fato, o trabalho de Ângela Alonso (2002) aprofundou a relação entre as práticas sociais e as construções intelectuais a partir da constatação que os membros da citada geração compartilhavam a experiência de estarem marginalizados das estruturas de poder do Império e, por isso, manifestavam-se nos meios intelectuais contra a ordem vigente como uma forma de atuação política. Para chegar a essa explicação, Alonso recorreu ao conceito de estrutura de oportunidades políticas de Sidney Tarrow, demonstrando que, em períodos de crise, como a desagregação da ordem imperial, emergem movimentos coletivos que até então estavam distantes das oportunidades políticas. No entanto, para que a geração de 1870 , tão heterogênea em suas origens sociais, ascendesse politicamente, precisou abusar de repertórios intelectuais importados, na acepção de Charles Tilly, que deram substrato a essa ação coletiva, como o positivismo.

Com uma preocupação distante daquela de Ângela Alonso (2002), encontra-se o trabalho de Alberto Grijó (1998). A partir da problemática levantada pela análise de trajetos sociais, orientou-se para a explicação das "origens sociais, estratégias de ascensão e recursos dos componentes da geração de 1907”. Em seu trabalho, Grijó (1998) articulou alguns elementos que explicam a ascensão na política nacional da chamada "geração de 1907", ${ }^{4}$ entre os quais: as faixas etárias e origens sociais comuns, a mesma formação escolar na Faculdade Livre de Direito de Porto Alegre, entre os anos de 1907 e 1908, e o ingresso na política em 1907, nas atividades do bloco acadêmico castilhista. Esses são alguns aspectos que compuseram essa "segunda geração de políticos republicanos rio-grandenses", que conquistaram espaço na burocracia do estado do Rio Grande do Sul e depois participaram das ações que levaram à Revolução de 1930.

Noutra direção, encontram-se os trabalhos de Sérgio Miceli $(1979,2001)$ e Daniel Pécault (1990). Ambos seguiram uma orientação comum - a análise dos intelectuais em condições periféricas ${ }^{5}-$, mas com pressupostos e método distintos. O estudo clássico de Sérgio Miceli (1979) sobre as elites dirigentes no Brasil argumenta que os intelectuais que aderiram ao Estado Novo eram originários da velha oligarquia rural decadente e aliaram-se ao Estado para manter suas posições de classe dirigente. Daniel Pécaut (1990) foi numa direção contrária ao mostrar que a questão do interesse desses intelectuais, ao ligaremse ao Estado, é ambígua, uma vez que os recursos mobilizados pelos intelectuais não se limitavam apenas à sua proximidade social com as elites; era também muito importante ter um saber socialmente valorizado. Desse modo, a condição de herdeiros sem herança não explicou por que esses intelectuais se sentiam investidos de uma missão política. Para Pécaut (1990), esses intelectuais agiam como uma categoria socialmente sem vínculos, no sentido atribuído por Mannheim, que estava desiludida com a República, e assim "sua politização não foi um pretexto para promover interesses próprios, mas, antes de tudo, ex- 
pressava sua conversão para a ação política” (p. 21).

Portanto, as análises sobre elites culturais e intelectuais circunscrevem-se em períodos históricos específicos. Sendo assim, o aporte da História é essencial para a compreensão da relação de certa esfera, seja a política, a cultural ou a intelectual, com os movimentos sociais em contextos periféricos, os quais não podem ser apreendidos apenas pelos esquemas conceituais utilizados em sociedades centrais. Além disso, a pesquisa histórica orientada pela metodologia das biografias e dos trajetos sociais, associada à produção intelectual e política dos agentes, como desenvolvemos abaixo, traz novas contribuições para a apreensão da realidade histórica e social em sua complexidade.

\section{Biografias, trajetos e tipologias}

A utilização de certas pesquisas históricas aliadas ao tratamento sociológico de dados renovou a área temática de elites sociais e culturais, tanto nas Ciências Sociais quanto na História. Isto se refere, mais diretamente, aos estudos sobre biografias e trajetórias sociais ligados à teoria dos campos de Pierre Bourdieu.

Mesmo que a busca por homologias entre os atributos de certa elite analisada diacronicamente, num espaço social específico, revele a persistência histórica de estruturas de dominação, isto não contradiz aqueles esquemas teóricos os quais indicam que até uma elite heterogênea em suas origens sociais pode agir intelectualmente e politicamente de forma homogênea, especialmente em contextos singulares, como nas mobilizações sociais nos contextos de crises estruturais.

Porém, ambas as perspectivas tendem a evitar uma análise balística, entre origem, posição e prática social e política, embora nem sempre, uma vez que, em se tratando de elites, há uma predisposição a análises determinísticas. ${ }^{6}$ De todo modo, tanto na História quanto nas Ciências Sociais, diante do fato de que os grandes construtos não explicam a totalidade do mundo social, dada a sua fragmentação, cada vez mais as análises têm privilegiado o indivíduo, ou o agente, do que as grandes estruturas sociais.

Uma das formas em que se desenvolvem essas análises é a abordagem das biografias. Uma biografia não se refere à história de vida, como o sentido comum entende, porque não existe uma sequência lógica de acontecimentos na vida de uma pessoa, ou seja, as vidas não têm um sentido teológico (Bourdieu, 1996a; Passeron, 1999). A biografia fornece os dados objetivados de dado indivíduo. Como cada indivíduo traz consigo incorporada uma série de disposições socialmente construídas que os posicionam no mundo social, é possível, a par- tir dos dados biográficos, localizar trajetos comuns que compartilham esses mesmos princípios geradores, ou seja, um habitus comum entre aqueles situados no mesmo grupo social (Bourdieu, 1996b). Conforme Bourdieu (1996b, p. 292), a biografia construída não é o último momento da análise científica, uma vez que:
A trajetória que ela visa reconstituir define-se como uma série de posições sucessivamente ocupadas por um mesmo agente ou por mesmo um grupo de agen- tes em espaços sucessivos [...]. É com relação aos es- tados correspondentes da estrutura do campo que se determinam em cada momento o sentido e o valor social dos acontecimentos biográficos, entendidos como colocações e deslocamentos nesse espaço ou, mais precisamente, nos estados sucessivos da estrutura da distribuição das diferentes espécies de capital que estão em jogo no campo, capital econômico e capital simbólico como capital específico de consagração.

Desse modo, quando Bourdieu e seu grupo falavam em trajetória, estavam se referindo à objetivação do habitus. São as trajetórias que revelam uma série de traços pertinentes de uma biografia individual ou de um grupo de biografias (Montagner, 2007). De forma diacrônica, as trajetórias revelam a série de posições sucessivamente ocupadas por um mesmo agente ou por um grupo de agentes no espaço social, assim como as mudanças engendradas na estrutura do campo em que esses agentes localizam-se e como se distribuem as diferentes espécies de capitais em jogo e os usos que os agentes fazem deles.

Esse tipo de recurso teórico-metodológico permite, em relação aos estudos históricos sobre elites sociais e políticas, além da reconstrução das trajetórias, revelar a persistência de estruturas sociais em dado período, ou dar indícios de mudança social. Nesse sentido,

O peso das disposições - portanto, a força explicativa da origem social - é particularmente grande quando se trata de uma posição em estado nascente, ainda antes por fazer do que ser feita, estabelecida, logo, capaz de impor suas normas próprias aos seus ocupantes; e, de maneira mais geral, que a liberdade deixada às disposições varia segundo o estado do campo (e, em particular da sua autonomia), segundo a posição ocupada no campo e segundo o grau de institucionalização do posto correspondente. (Bourdieu, 1996b, p. 300)

Portanto, esse tipo de análise é muito útil em períodos históricos situados que revelem que tipos de recursos eram indispensáveis para constituir a elite social e/ou política do período. Dessa forma, isto está relacionado com o processo de autonomização em relação às outras esferas sociais em curso no campo em que o agente está 
inserido. Embora Lahire (2002) critique o modelo de unicidade do ator de Pierre Bourdieu, porque os hábitos ou esquemas de ação que cada ator pode ter interiorizado dependem da coerência dos princípios de socialização aos quais esteve sujeito, para o estudo de elites esse modelo, desde que localizado historicamente, ainda é válido, uma vez que a crítica de Bernard Lahire (2002) em questão refere-se àqueles que não se enquadram na teoria dos campos de Pierre Bourdieu, a qual:

1) Ignora as incessantes passagens operadas pelos agentes que pertencem a um campo entre o campo dentro do qual são produtores, os campos nas quais são simples consumidores/ espectadores e as múltiplas situações que não são referíveis a um campo, reduzindo o ator a seu ser-como-membro de um campo; 2) Negligencia a situação daqueles que se definem socialmente (e se constituem mentalmente) fora de toda atividade num campo determinado (é o caso ainda das numerosas donas de casa sem atividade profissional ou pública) e 3) Considera os fora-de-campo, os sem-grau, a partir dos padrões de medida que são padrões sociais de medida de poder (diploma, renda, etc), definindo seu habitus pela falta de posses, por sua miséria e pela sua situação de dominados. Por todos esses motivos a teoria dos campos não pode, certamente, ser uma teoria geral e universal, mas representa uma teoria regional do mundo social. (Lahire, 2002, p. 35)

Assim, mesmo que essa teoria não possa ser tida como universal, muitos dos seus pressupostos abrangem as problemáticas direcionadas aos estudos das elites sociais e políticas. Dessa forma, a partir da prosopografia, como veremos mais adiante, é possível descobrir as homogeneidades nos grupos de elites que justifiquem as tomadas de posição semelhantes que vão refletir-se nas suas produções intelectuais, além de tipificar aqueles casos mais representativos, dentre as evidências empíricas, para fins da análise sociológica, ou política, assim como descobrir aqueles casos que não se enquadram, em termos de recursos, disposições etc, no grupo analisado (Miceli, 2001).

\section{O aporte da análise prosopográfica}

Trabalhos sobre elites utilizando-se da análise prosopográfica emergiram, sobretudo, a partir dos anos 1970. A partir desse período, Christofhe Charle (2006a) identificou três enfoques predominantes. O primeiro esteve preocupado em determinar a composição dos parlamentos, das elites administrativas e das elites locais em períodos históricos determinados. Os outros dois, com base no recorte da reprodução social, analisaram os corpos administrativos ou as grandes escolas na segunda metade do século XX, assim como as elites culturais e universitárias.

Anteriormente, porém, a utilização do método prosopográfico estava circunscrita à história da Antiguidade e da Idade Média, por meio da análise do pessoal administrativo e do entourage dos grandes soberanos dos principais Estados da Europa. Na França e na Itália, o interesse nesse período recaía sobre os diferentes corpos de funcionários ou de magistrados e sobre as elites eclesiásticas, intelectuais, financeiras ou comerciais (Charle, 2006b).

$\mathrm{Na}$ segunda metade dos anos 60 , a análise prosopográfica foi reintroduzida em alguns países pela influência das teorias elitistas de Pareto e Mosca e, no caso especifico da França, pela ascensão de teorias alternativas à marxista na interpretação da Revolução Francesa por meio da prosopografia das elites antes e depois da revolução (Charle, 2006b). De todo modo, todos esses estudos ainda estão ligados ao domínio da história dos notáveis do século XIX ou da formação histórica da burguesia. Somente depois dos anos 70, especialmente com os trabalhos de Pierre Bourdieu e de seu grupo, que o método prosopográfico aproximou-se das questões expostas pela sociologia. ${ }^{7}$ Nesse sentido que Flávio Heinz (2006) definiu o método prosopográfico:

A prosopografia, ou método das biografias coletivas, pode ser considerada um método que utiliza um enfoque de tipo sociológico em pesquisa histórica, buscando revelar as características comuns (permanentes ou transitórias) de um determinado grupo social em dado período histórico. (Heinz, 2006, p. 9)

Desse modo, a análise de biografias coletivas possibilita desvendar aspectos sociológicos de determinados grupos, como os perfis sociais, o recrutamento e a reprodução social, num dado contexto histórico determinado. No entanto, pode ir além da análise meramente sociográfica ao:

Explicar a mudança ideológica ou cultural, identificar a realidade social, descrever e analisar com precisão a estrutura da sociedade e o grau e a natureza dos movimentos que se dão no seu interior. (Stone, 1981, p. 45-46, apud Heinz, Flávio, 2006, p. 9)

Para tanto, nessa passagem do nível micro ao macro de interpretação através da análise das biografias coletivas, alguns aspectos devem ser considerados. Por um lado, a biografia não representa apenas uma pessoa singular, mas, acima de tudo, um indivíduo 
que concentra todas as características de um grupo, ou seja, reproduz a estrutura social (Levi, 1989). Logo, em termos de análise sociológica, a descrição das categorias sociais do grupo em questão revela a estrutura de dominação da sociedade em que estão inseridos ou as mudanças ocorridas na seleção e na reprodução das elites com o processo de institucionalização de certas esferas sociais. Por outro lado, a análise prosopográfica pode trazer novos elementos à interpretação histórica, especialmente sobre as mudanças sociais, culturais e ideológicas em períodos de transição política (Hunt, 2007).

Porém, a prosopografia apresenta certas limitações. A primeira refere-se ao fato de que esse método não abrange a totalidade dos grupos sociais, uma vez que apenas aqueles indivíduos pertencentes às posições sociais, culturais e políticas mais altas estão bem documentados nos arquivos e dicionários biográficos. Mesmo sobre estes as informações encontradas podem ser escassas em relação à parte da amostra. Isto reduziria as variáveis analisadas através do questionário aplicado à totalidade das biografias. Dessa forma, deve-se precisar o tamanho da amostra na impossibilidade de abarcar todas as variáveis em estudo, conforme adverte Charle (2006a, p. 31), quanto "mais seu questionário é longo, mais sua população alvo precisa ser precisa; a escolha do alvo é primordial, pois uma amostragem arbitrária pesará permanentemente sobre os resultados" e uma alternativa para tanto seria recorrer a "pequenas amostras, saturadas de informação e, se possível, comparáveis entre si ou com aquelas de outros pesquisadores".

Portanto, o processo de pesquisa histórica prosopográfico consiste na delimitação da amostra, no levantamento da documentação e, a partir disso, na criação de notas biográficas padronizadas conforme as variáveis levantadas no questionário, demonstrando as similaridades e particularidades da população investigada, essencialmente de forma quantitativa. Contudo, esses procedimentos não explicam aqueles casos individuais que exibem características sociais diferenciadas dentro do grupo analisado (Roy e Saint-Pierre, 2006).

Essa limitação está relacionada ao fato de que o método prosopográfico desenvolveu-se juntamente com a popularização dos softwares de análise quantitativa. ${ }^{8}$ Consequentemente, para dar conta da explicação da estrutura social através das biografias coletivas de grupos socialmente relevantes, esse método carece de outras variáveis relacionadas com os processos históricos, políticos e sociais em curso, ou seja, os aspectos qualitativos. Desse modo, os historiadores sociais, além de buscarem determinar os atributos sociais, políticos, demográficos etc., para explicar as mudanças e/ ou con- tinuidades sociais e históricas a partir das elites, devem combinar a prosopografia com outras metodologias.

De toda forma, pela prosopografia, podem-se demonstrar tanto a reprodução social consequente das lógicas empregadas na manutenção da estrutura social quanto as lutas para a transformação da estrutura de poder em cada esfera social. Nesse sentido, a prosopografia é um aporte muito útil nas análises de elites sociais e políticas.

\section{Considerações finais}

Esse breve quadro da relação entre pesquisa histórica e interpretação sociológica no estudo de elites em seu sentido geral sugere algumas implicações. A primeira, e mais importante, é o risco de fazer análises descontextualizadas, que tomam as lutas e as lógicas dos grupos e dos agentes como explicativas dos processos históricos. Dito de outra forma, refere-se ao fato de o pesquisador abrir mão da pesquisa documental do período em questão como uma fonte explicativa importante.

A segunda questão é que, ao enfatizar os atributos e recursos sociais como representativos da estrutura social à qual o agente está inserido, relega-se suas práticas sociais objetivadas nas suas próprias produções intelectuais, políticas, a um segundo plano. Não estamos sugerindo que todos os trabalhos produzidos a partir dessa imbricação da pesquisa histórica com a interpretação sociológica privilegiem a história intelectual, mas que elas sejam levadas também em conta na análise das práticas sociais.

Com efeito, a agenda de pesquisas sobre elites sociais e políticas ganhou muito mais impulso através da incorporação de temas e pesquisas históricos. Isto foi uma das preocupações de Pierre Bourdieu e de seu grupo em relação ao contexto francês e em muito se deve a esses trabalhos a importação desse tipo de problemática para contextos periféricos. Contudo, essa importação não deve deixar de demarcar as especificidades históricas e sociais de cada contexto, uma vez que não somente as elites são produtos históricos, mas seu estudo revela o processo em curso ou não de autonomização de cada esfera no espaço social.

Assim, ao se fazer uma história social de certas instituições políticas, culturais etc., como da história social do político, do intelectual, não se corre aquele risco, muito prejudicial às Ciências Sociais, de tomar os recursos e atributos de certos grupos sociais com influência em certas instituições como explicativos em si mesmos, não levando-se em conta a contextualização e a mudança histórica, tanto dos atributos dos agentes situados nos grupos de elites quanto dos seus 
pertencimentos sociais. Portanto, ao não se pressupor a existência de uma esfera autônoma, põem-se em evidência configurações políticas e sociais significativas para a compreensão tanto da relação entre elites e instituições quanto do peso de certos pertencimentos sociais nos repertórios de ação disponíveis em certos períodos históricos determinados.

\section{Referências}

ALONSO, Angela. Ideias em movimento: A geração 1870 na crise do Brasil-Império. São Paulo: Paz e Terra, 2002.

GUIMARÃES, Nadya Araujo. Entrevista com Charles Tilly. Tempo Social, v.16, n. 2, 2004. ALTAMIRANO, Carlos. Ideias para um programa de História intelectual. Dossiê História Social dos Intelectuais Latino-Americanos. Tempo Social, junho, v. 19, n.1, p. 9-17, 2007.

AULIARD, Claudine. Création et exploitation d'une banque de donnés informatisées relative aux activités diplomatiques de Rome de 753 à 31 av. J-C. Dialogues d'histoire ancienne, n. 11, p. 86-108, 1985.

BOURDIEU, Pierre.As regras da arte. Gênese e estrutura do campo literário. São Paulo: Companhia das Letras, 1996a.

. A ilusão biográfica. Razões práticas:

Sobre a teoria da ação. Campinas, Papirus, 1996b.

BURKE, Peter. Veneza e Amsterdã: um estudo das elites do século XVII. São Paulo: Brasiliense, 1981.

CARVAlHO, José Murilo. A construção da ordem. A elite política imperial. Rio de Janeiro: Campus, 1980.

CHARLE, Christophe. Como anda a história social das elites e da burguesia? In: HEINZ, Flávio (Org). Por outra história das elites. Rio de Janeiro: Editora FGV, 2006a.

A prosopografia ou biografia co-

letiva: balanço e perpectivas. In: HEINZ, Flávio (Org). Por outra história das elites. Rio de Janeiro: Editora FGV, 2006b.

CONINCK, Frédéric de; GODARD, Francis. L'approche biographique à l'épreuve de l'interprétation. Les formes temporalles de la causalité. Revue Française de Sociologie, XXXI, p. 25-53, 1989.

CORADINI, Odacir Luiz. Em nome de quem? Rio de Janeiro: Relume Dumará, 2001.

DAHL, Robert. Who governs? New Haven: Yale University Press, 1961.

GENET, Jean-Philippe. L'informatique a service de la prosopographie: Prosop. Mélanges de l'école française de Rome. Moyen-Age. Temps Modernes, v. 100, n. 1, p. $247-$ 263, 1988.

GRIJÓ, Luiz Alberto. Origens sociais, estratégias de ascensão e recursos dos componentes da chamada "geração de 1907". Porto Alegre, 1998. Dissertação (Mestrado em Ciência Política) - UFRGS

GRILL, Igor Gastal. As bases sociais dos compromissos: a constituição de um espaço de concorrência eleitoral do sul do Rio Grande do Sul. Porto Alegre, 1999. Dissertação (Mestrado em Ciência Política) - UFRGS.

GRYNSZPAN, Mário. Ciência, política e trajetórias sociais: uma sociologia histórica da teoria das elites. Rio de Janeiro: Editora FGV, 1999

HEINZ, Flávio. O historiador e as elites - à guisa de introdução. In: HEINZ, Flávio (Org). Por outra história das elites. Rio de Janeiro: Editora FGV, 2006.

HUNT, Lynn. Política, cultura e classe na Revolução Francesa. São Paulo: Companhia das Letras, 2007.

LAHIRE, Bernard. Homem plural. Os determinantes da ação. Petrópolis, RJ: Vozes, 2002.

LEVI, Giovanni. Les usages de la biographie. Annales, Histoire, Sciences Sociales, v. 44, n. 6, p. 1325-1336, 1989.

MARTUSCELLI, Danilo Henrico. Para uma crítica ao marxismo elitista. In: ENCONTRO ANUAL DA ANPOCS, 31, 2007, Caxambu, MG.

MELO JÚNIOR, João Alfredo C. C. A ação coletiva e seus intérpretes. As perspectivas teóricas de Charles Tilly e Mancur Olson. In: SIMPÓSIO NACIONAL DE HISTÓRIA - ANPUH, 24, 2007, São Leopoldo, RS.

MICELI, Sérgio. Intelectuais e classe dirigente no Brasil (19201945). São Paulo: Difel, 1979.

. Intelectuais à brasileira. São Paulo: Com-

panhia das Letras, 2001.

MONTAGNER, Miguel Ângelo. Trajetórias e biografias: notas para uma análise bourdieusiana. Sociologias, n. 17, jan/jun, p. 240-264, 2007.

NEIBURG, Federico. Os intelectuais e a invenção do peronismo. São Paulo: Edusp, 1997.

PAMPLONA, Marco. A historiografia sobre o protesto popular: Uma contribuição para o estudo das revoltas urbanas. Revista Estudos Históricos, n. 17, 1996.

PASSERON, Jean-Claude. Biographie, flux, itinéraires, trajectoires. Revue Française de Sociologie, XXXI, 1989.

PÉCAULT, Daniel. Os intelectuais e a política no Brasil. São Paulo: Ática, 1990.

PUTNAM, Robert. The comparative study of political elites. New Jersey: Prentice- Hall, 1976.

RÉMOND, René (Org.). Por uma história política. Rio de Janeiro: Ed. UFRJ/Ed. FGV, 1996.

RINGER, Fritz. O declínio dos mandarins alemães: A comunidade acadêmica alemã, 1890-1933. São Paulo: Ed.USP, 2000. RIOUX, Jean-Pierre; SIRINELLI, Jean-François. Histoire culturelle de la France - Le temps des masses, Le XXe Siècle, tome 4. Paris: Seuil, 2005.

ROY, Fernande; SAINT-PIERRE, Jocelyn. A alta redação dos jornais de Québec (1850-1920). In: HEINZ, Flávio (Org). Por outra história das elites. Rio de Janeiro: Editora FGV, 2006.

SANTOS, André Marenco dos. Não se fazem mais oligarquias como antigamente. Recrutamento parlamentar, experi- 
ência política e vínculos partidários entre deputados brasileiros [1946-1998]. Porto Alegre, 2000. Tese (Doutorado em Ciência Política) - UFRGS.

; SERNA, Miguel. Por que carreiras políticas na esquerda e na direita não são iguais? Recrutamento legislativo em Brasil, Chile e Uruguai. Revista Brasileira de Ciências Sociais, V. 22, n. 64, p. 93-113, 2007.

SERNA, Miguel. La política como profesión y las profesiones de la política: El Uruguay desde la sociología. Montevideo: Departamento de Sociología, Udelar, 2007.

SCOTT, John. Les élites dans la sociologie anglo-saxonne. In: SULEIMAN, Ezra; MENDRAS, Henri. Le recrutement des élites en Europe. Paris: Editions La Découverte, 1995.

SKOCPOL, Theda. El Estado regresa al primer plano: estrategias de análisis en la investigación actual. Zona Abierta, n. 50, p. 71-122, 1989.
SIGAL, Silvia. Le rôle politique des intellectuels en Amérique Latine: la derive des intellectuels en Argentine. Paris: L'Harmattan, 1996.

SIRINELLI, Jean-François.Intellectuels et passions françaises. Paris, Fayard, 1990.

Générations et histoire politique. Vingtième siècle: Révue d'Histoire, n. 22, 1989.

TARROW, Sidney. Power in movement. Social movements, collective action and politics. Cambridge: Cambridge University Press, 1994.

TILLY, Charles.From mobilization to revolution. Reading, Massachussets: Addison-Wesley, 1978.

Contentions repertoires in Great Britain, 17581834. Social Science History, v.17, n. 2, 1993.

Grandes estructuras, procesos amplios, comparaciones enormes. Madrid: Alianza Editorial, 1991.

\title{
Studies on political and social elites: contributions from sociology and history
}

\begin{abstract}
This work has the purpose of analyzing the relation between sociological analysis and historically situated elites. This choice is justified for two reasons: first, because the overlapping of historical research and sociological studies on the elites has been a dominant subject in the Social Sciences in the last decades, especially in France, and second, due to the fact that the theoretical and methodological analysis of this relation lacks delimitations, especially in order to analyze the intellectual elites in peripheral contexts, as is the case of Brazil. Thus, we demonstrate, initially, how those theoretical projects had been used in some historical research. Following that, we approach the type of sociological treatment used over historical trajectories, both individual and in groups of elites. We demonstrate, therefore, one of the methodological resources available between historical research and sociological analysis: prosopography.
\end{abstract}

Key words: elites; sociology; history; prosopography.

\section{Estudio de Elites Políticas y Sociales: Las contribuciones de la Sociología y de la Historia}

\section{Resumen}

Este trabajo tiene como objetivo analizar la relación entre el análisis sociológico y las elites situadas históricamente. Esta elección se justificó por dos razones: primer, porque en las últimas décadas la imbricación entre la pesquisa histórica y los estudios sociológicos sobre elites es un tema dominante en las Ciencias Sociales, especialmente en Francia, y, segundo, porque el análisis teórico-metodológico de esa relación carece de delimitaciones, especialmente para analizar las elites intelectuales en contextos periféricos, como es el caso de Brasil. De ese modo, demostramos, en un primer momento, como esos esquemas teóricos fueron utilizados en algunas pesquisas históricas. Enseguida, abordamos el tipo de tratamiento sociológico empleado en las trayectorias históricas, tanto individuales como de grupos de elites, para, por fin, exponer uno de los recursos metodológicos disponibles entre la pesquisa histórica y el análisis sociológico: la prosopografía.

Palabras clave: elites; sociología; historia; prosopografía. 